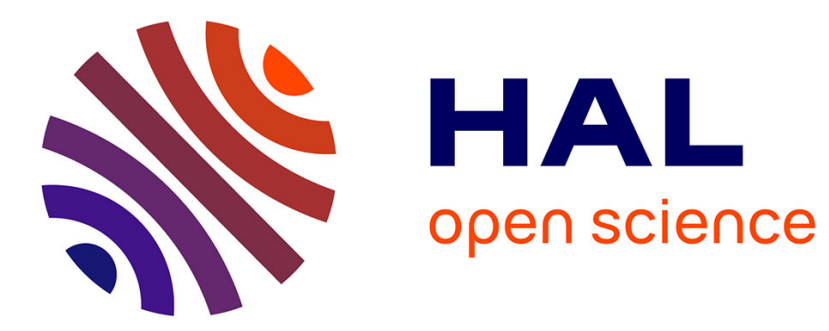

\title{
Pressure effects on the soot production and radiative heat transfer of non-buoyant laminar diffusion flames spreading in opposed flow over insulated wires
}

\author{
Augustin Guibaud, J.L. Consalvi, J.M. Citerne, Guillaume Legros
}

\section{To cite this version:}

Augustin Guibaud, J.L. Consalvi, J.M. Citerne, Guillaume Legros. Pressure effects on the soot production and radiative heat transfer of non-buoyant laminar diffusion flames spreading in opposed flow over insulated wires. Combustion and Flame, 2020, 222, pp.383-391. hal-03189029

\section{HAL Id: hal-03189029 \\ https://hal.science/hal-03189029}

Submitted on 28 Apr 2021

HAL is a multi-disciplinary open access archive for the deposit and dissemination of scientific research documents, whether they are published or not. The documents may come from teaching and research institutions in France or abroad, or from public or private research centers.
L'archive ouverte pluridisciplinaire $\mathbf{H A L}$, est destinée au dépôt et à la diffusion de documents scientifiques de niveau recherche, publiés ou non, émanant des établissements d'enseignement et de recherche français ou étrangers, des laboratoires publics ou privés. 


\title{
Pressure Effects on the Soot Production and Radiative Heat
}

\section{Transfer of Non-Buoyant Laminar Diffusion Flames Spreading in Opposed Flow over Insulated Wires}

\author{
Augustin Guibaud $^{1}$, Jean-Louis Consalvi ${ }^{2, \dagger}$, Jean-Marie Citerne ${ }^{1}$, Guillaume Legros ${ }^{1,3}$ \\ ${ }^{1}$ Sorbonne Université, CNRS, UMR 7190, Institut Jean Le Rond d'Alembert, Paris F-75005, France \\ ${ }^{2}$ Aix-Marseille Université, CNRS, IUSTI UMR 7343, 5 rue E. Fermi, 13013 Marseille, France. \\ ${ }^{3}$ INSIS/CNRS, 1C av. de la Recherche Scientifique, 45071 Orléans cedex 2, France \\ ${ }^{\dagger}$ Corresponding author. Fax: (+33)491106969. Email: jean-louis.consalvi@univ-amu.fr
}

\begin{abstract}
:
This paper investigates experimentally and numerically pressure effects on soot production and radiative heat transfer in non-buoyant opposed-flow flames spreading over wires coated by Low Density PolyEthylene (LDPE). Experiments, conducted in parabolic flights, consider pressure levels ranging from $50.7 \mathrm{kPa}$ to $121.6 \mathrm{kPa}$ and an oxidizer flowing parallel to the wire's axis at a velocity of $150 \mathrm{~mm} / \mathrm{s}$ and composed of $20 \% \mathrm{O}_{2} / 80 \% \mathrm{~N}_{2}$ in volume. The numerical model includes a detailed chemistry, a two-equation smoke-point based soot production model, a radiation model coupling the Full-Spectrum correlated-k method with the finite volume method and a simple degradation model for LDPE. An analysis of the experimental data shows that the spread rate, the pyrolysis mass flow rate, and the residence time for soot formation are independent of pressure whereas the soot formation rate is third-order in pressure. The model reproduces quantitatively the effects of pressure on soot production and captures the transition from non-smoking to smoking flames. The radiant fraction increases with pressure because of
\end{abstract}


an enhancement in soot radiation whereas the contribution of radiating gases remains approximately constant over the range of pressures considered. In addition, gas radiation dominates at pressure lower than $75 \mathrm{kPa}$ whereas soot radiation prevails at higher-pressure levels. Consistently with the data obtained at normal gravity, the smoke-point transition is found to occur for a radiant fraction of about 0.3 and the soot oxidation freezing temperature is estimated in the range 1350-1450K. Eventually, whatever the pressure considered, the surface re-radiation from the wire is higher than the incident radiative flux from the flame to the surface along the entire wire. This shows that radiative heat transfer contributes negatively to the heating of the unburnt LDPE and to the heat balance along the pyrolysing surface.

Key Words: Opposed-Flow Flame Spread, Electrical Wire, Microgravity, Pressure Effects, Soot Radiation

\section{Nomenclature}

$a \quad$ stretch function $[-]$

$A_{S} \quad$ soot surface area $\left[\mathrm{m}^{-1}\right]$

f $\quad$ k-distribution function $\left[\mathrm{m}^{-1}\right]$

$f_{s} \quad$ soot volume fraction $[-]$

$g \quad$ cumulative $k$-distribution function [-]

$g_{0} \quad$ cumulative $k$-distribution function in the reference state[-]

$I_{g}, I \quad$ radiative intensity $\left[\mathrm{W} \cdot \mathrm{m}^{-2} \cdot \mathrm{sr}^{-1}\right]$

$I_{b} \quad$ blackbody intensity (Planck function) $\left[\mathrm{W} \cdot \mathrm{m}^{-2} \cdot \mathrm{sr}^{-1}\right]$ 


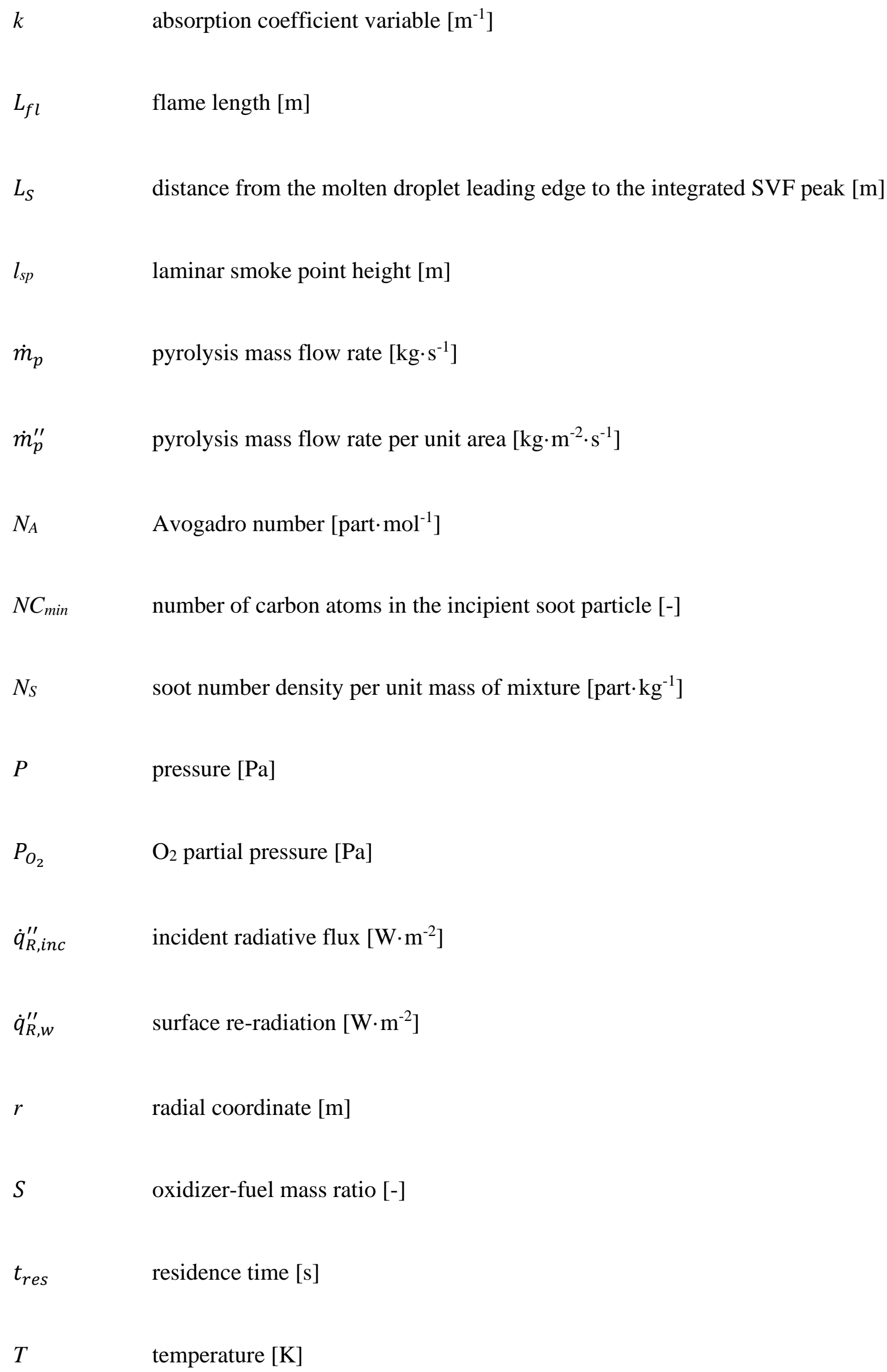




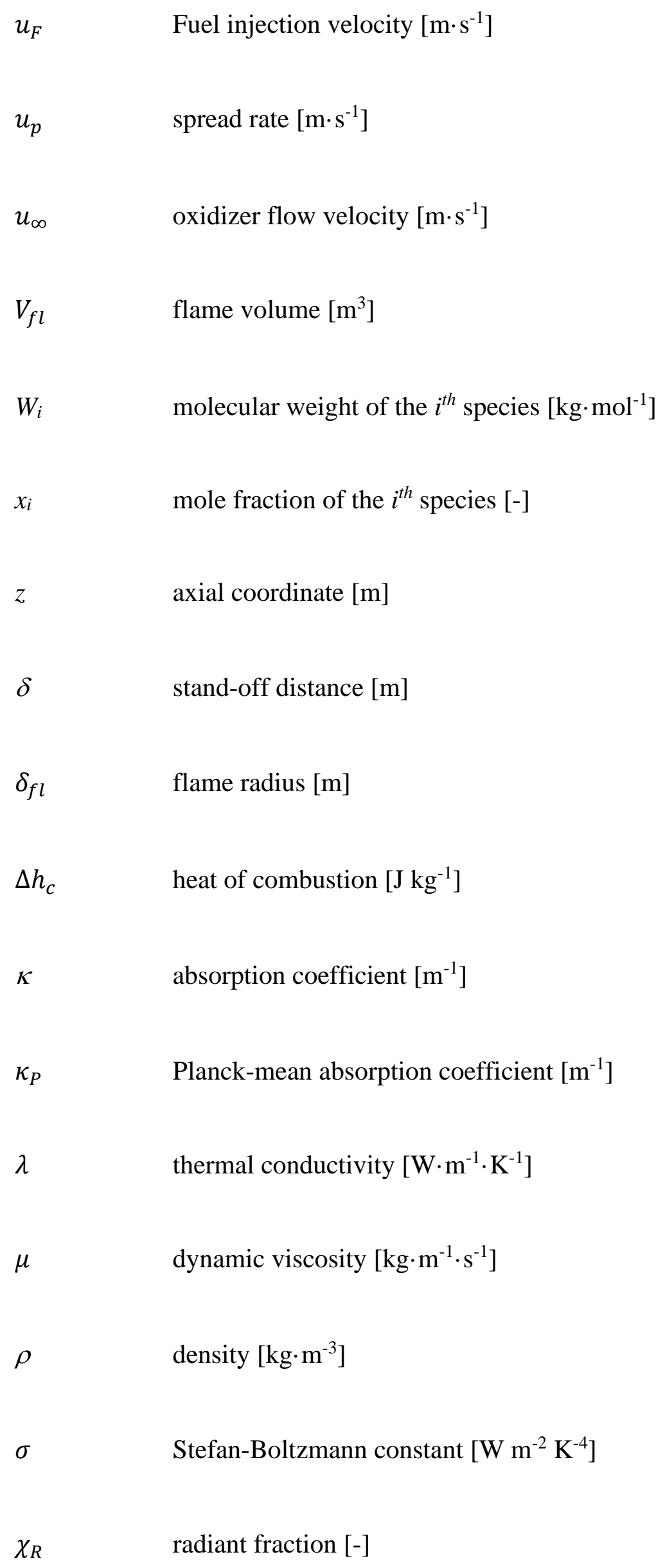




\begin{tabular}{|c|c|}
\hline$\chi_{R, g}$ & gas contribution to the radiant fraction $[-]$ \\
\hline$\chi_{R, s}$ & soot contribution to the radiant fraction $[-]$ \\
\hline$\dot{\omega}_{\text {coag }}$ & reaction rate for soot coagulation $\left[\mathrm{part} \cdot \mathrm{m}^{-3} \cdot \mathrm{s}^{-1}\right.$ ] \\
\hline$\dot{\omega}_{n}$ & reaction rate for soot nucleation $\left[\mathrm{mol} \cdot \mathrm{m}^{-3} \cdot \mathrm{s}^{-1}\right]$ \\
\hline$\dot{\omega}_{N_{S}}$ & reaction rate for soot number density $\left[\mathrm{part} \cdot \mathrm{m}^{-3} \cdot \mathrm{s}^{-1}\right]$ \\
\hline$\dot{\omega}_{\mathrm{O}_{2}}$ & reaction rate for soot oxidation by $\mathrm{O}_{2}\left[\mathrm{~kg} \cdot \mathrm{m}^{-2} \cdot \mathrm{s}^{-1}\right]$ \\
\hline$\dot{\omega}_{O H}$ & reaction rate for soot oxidation by $\mathrm{OH}\left[\mathrm{kg} \cdot \mathrm{m}^{-2} \cdot \mathrm{s}^{-1}\right]$ \\
\hline$\dot{\omega}_{s f}$ & reaction rate for soot surface growth $\left[\mathrm{kg} \cdot \mathrm{m}^{-3} \cdot \mathrm{s}^{-1}\right]$ \\
\hline$\dot{\omega}_{Y_{S}}$ & source term for soot mass fraction $\left[\mathrm{kg} \cdot \mathrm{m}^{-3} \cdot \mathrm{s}^{-1}\right]$ \\
\hline Subscr & \\
\hline$b$ & molten ball \\
\hline$f l$ & flame \\
\hline$g$ & gas \\
\hline inc & incident \\
\hline $\max$ & maximum \\
\hline$p$ & pyrolysis \\
\hline$P E$ & polyethylene \\
\hline
\end{tabular}


radiation or radiative

$s p$

smoke point

$s$

soot

$\infty$

ambient

0

reference

Acronyms

BMAE Broadband Modulated Absorption Emission

FSCK $\quad$ Full-Spectrum correlated-k

LDPE low density polyethylene

LSP laminar smoke point

PE polyethylene

SF $\quad$ soot formation

SP $\quad$ smoke point

SVF $\quad$ soot volume fraction

\section{Introduction}

Unexpected overheating of wires by electrical current overshoots has been identified as a primary cause of fire initiation and growth in a space vehicle. This has motivated a significant amount of experimental [1]-[4] and numerical [5],[6] studies related to laminar flame spread 
over thin electrical wires in microgravity. This motivation has been reinforced by the inherent differences between non-buoyant and buoyant laminar diffusion flame structures [7] that do not allow the conclusions drawn at earth gravity to be extended to microgravity. Ambient conditions, such as pressure, oxygen content, and slow forced flow due to ventilation are expected to affect flame spread characteristics. Among these parameters, oxygen content and ambient pressure are intimately related in space exploration applications.

Ranging from conservative Earth-like conditions to ambitious low-pressure and high oxygen content environment, past spacecraft designs have incorporated one of the following three sets of pressure and oxygen content: i) pure molecular oxygen $\left(x_{O_{2}}=1\right)$ at a reduced pressure, $P$, of $34.5 \mathrm{kPa}$ (Mercury, Gemini, and Apollo missions), ii) nominal mixture composed by $21 \%$ $\mathrm{O}_{2}$ and $79 \% \mathrm{~N}_{2}\left(x_{O_{2}}=0.21\right.$ and $\left.x_{N_{2}}=0.79\right)$ and at sea-level pressure $P=101.3 \mathrm{kPa}$ (Vostok, Voskhod, Orbiter, Spacelab, MIR, International Space Station, Soyuz, and Shenzhou missions), and iii) oxygen-enriched low pressure mixture with $x_{O_{2}}=0.72$ and $x_{N_{2}}=0.28$ at $P=34.5 \mathrm{kPa}$ (Skylab Space Station) [8]. In the near future, exploration atmosphere is likely to be an oxygen-enriched mixture at low pressure, with current target for the Orion MultiPurpose Crew Vehicle of $x_{\mathrm{O}_{2}}=0.34$ and $x_{N_{2}}=0.66$ at $P=56.5 \mathrm{kPa}$ [7]. It should be pointed out that none of these atmospheric conditions are fire safe since the flammability limit of most of hydrocarbons is about $15 \%$ in terms of $\mathrm{O}_{2}$ mole fraction regardless of pressure. Fire incidents have been documented aboard Apollo 13 [9], Salyut-1 [10],[11], Salyut-6 [12], the Orbiter fleet [13], and Mir [14]. In addition, the vast majority of incidents report surprising large amounts smoke [15], which raises doubts regarding the future safety of astronauts onboard the Orion spacecraft in the context of long-range missions. Consequently, understanding how ambient parameters affect the onset of smoke release is crucial towards the development of a safe space exploration framework. 
In order to precisely break down the mechanisms responsible for the transition from nonsmoking to smoking-flames, a special emphasis must be put on soot production and the related radiative heat transfer processes. Previous studies considering non-buoyant axisymmetric laminar diffusion flames fueled by gaseous hydrocarbons showed that, as observed at normal gravity [16]-[18], the soot production and therefore soot radiation increase with pressure [19],[20]. A consequence of this increase in fuel sooting propensity with pressure is that the laminar smoke point (LSP) flame length is inversely proportional to pressure [20]. The mechanisms leading to the SP were found similar at both normal and microgravity and were identified as the quenching of the soot oxidation process at the flame tip owing to the radiative cooling mainly caused by soot radiation. However, the SP characteristics in microgravity were found different from those observed at earth gravity. First, non-buoyant SP flame lengths are significantly shorter for comparable conditions [20]. Moreover, the SP radiant fraction and the soot oxidation freezing temperature for microgravity were reported to be in the range 0.4-0.6 [19] and $1000 \mathrm{~K}$ [20], respectively, as compared to 0.3 [21] and the range 1300-1450 K [22][24] at normal gravity.

In addition to these gas-phase phenomenological discrepancies, alterations in flame spread rate are well documented in various configurations in the absence of buoyancy [2],[7],[25]. Since flame spread controls the fuel pyrolysis and, in turn, the flame geometry and residence time, these modifications increased doubts in the ability of standard tests conducted at normal gravity to successfully forecast smoking properties of a given material. Investigations of SP mechanisms over a spreading flame thus combine both effects to provide a holistic perception of the definite effects of flow conditions.

The present paper focuses on the soot production, the SP mechanisms and radiative structures of laminar diffusion flames spreading in an opposed flow configuration over idealized electrical 
wires. The main advantage of the wire configuration is that its $2 \mathrm{D}$ axisymmetric geometry allows the BMAE (Broadband Modulated Absorption Emission) technique, cautiously developed by the authors [26],[4], to be implemented, which leads to the concomitant measurements of soot volume fraction and temperature in the spreading flame. The wires consist of a Nickel-Chrome (NiCr) metallic core coated with Low Density PolyEthylene (LDPE) and differ from the non-flammable polyimide wire insulation (MIL-W-81381) mostly employed in spacecraft [27]. However, although LDPE coated wires are not employed in space vehicles as such, their consideration is relevant for several reasons. First, it corresponds to an international target configuration to investigate fundamentally the flammability properties of electrical wires. Their use has emerged with the work of Bakham et al. [28] and, over the last twenty years, a significant amount of experimental studies, mainly related to fire safety in spacecraft, have adopted the PE coated wire configuration [3], [4], [29]-[34]. Second, it produces soot volume fraction levels above the detection threshold of the BMAE over the range of pressure considered in the present study. The lower limit of the pressure range was selected to be above this threshold and the range was calibrated to observe the transition from a nonsmoking flame to a smoking one. Finally, PE is a potential spacecraft material considered for space radiation shielding [35], and hence requires a careful evaluation of its flammability properties. The present work is organized as follows. The second section presents the experimental setup and optical diagnostics. The numerical model is presented in section 3 . The experimental and numerical results are discussed in section 4 whereas section 5 summarizes the main conclusions of the paper.

\section{Experiments}

Experiments were conducted in parabolic flights. The experimental setup and the optical diagnostics are detailed in Ref. [4] and are only briefly described here. The experimental setup 
consists of a cylindrical combustion chamber with an inner diameter of $190 \mathrm{~mm}$. Cylindrical wires of length $150 \mathrm{~mm}$, consisting of a $0.5 \mathrm{~mm}$ diameter $\mathrm{NiCr}$ core coated by a $0.3 \mathrm{~mm}$ thick LDPE insulation, are placed along the central axis of the chamber. Laminar oxidizer flows of velocity $150 \mathrm{~mm} / \mathrm{s}$, parallel to the sample axis and composed of $20 \% \mathrm{O}_{2} / 80 \% \mathrm{~N}_{2}$ in volume, were generated. The pressure was varied between 50.7 and $121.6 \mathrm{kPa}$. The samples were ignited using a hot Kanthal wire, resulting in an opposed-flow flame spread.

Images were captured using a JAI AT-140CL digital tri-CCD camera, equipped with a telecentric lens to restrict the light collection to beams parallel to the optical axis. With this arrangement, the spatial resolution of the projected data is $76 \mu \mathrm{m}$ over the two spectral bands of interest for the BMAE, ranging from $480 \mathrm{~nm}$ to $600 \mathrm{~nm}$ (green) and from $570 \mathrm{~nm}$ to $700 \mathrm{~nm}$ (red), respectively. Images were acquired at a rate of $39.06 \mathrm{fps}$ and a LEDs backlight behind the samples is alternatively set on and off.

Flame spread rate, pyrolysis mass flow rate, SVF and temperature are determined using image processing once a steady flame spread is reached. The flame is assumed to spread at a steady rate once the dimensions of the characteristic molten insulation droplet (see Fig. 1), the visible flame length, and the rate of the flame front displacement reach a steady state value [4]. The flame spread rate, $u_{p}$, is evaluated by tracking the time evolution of the luminous flame front. The pyrolysis rate, $\dot{m}_{p}$, is then evaluated from $u_{p}$ assuming a constant LDPE density of $\rho_{P E}=$ $920 \mathrm{~kg} / \mathrm{m}^{3}$

SVF and temperature fields are obtained using the B-MAE technique as extensively outlined in Ref. [26]. As discussed in the introduction, the implementation of the BMAE takes advantage of the axisymmetric geometry of the present configuration. These fields can be extracted from a set of four images: the flame with backlight, the backlight alone, the flame alone, and the background noise. The technique assumes that soot radiates within the Rayleigh regime. The 
soot absorption coefficient is computed using the refractive indexes provided by Chang and Charalampopoulos [36]. The transmission fields over each spectral range, obtained by subtracting images with and without backlight, allows to recover the SVF. As the information is integrated over line-of-sights, a deconvolution procedure, involving an onion-peeling method combined with a Tikhonov regularization, is required. The frames captured over the two spectral ranges in the absence of backlight are then processed to retrieve the temperature. Soot reabsorption is taken into account in the onion-peeling deconvolution process since it is nonnegligible over the spectral ranges involved in the BMAE. This technique allows SVF and temperature to be recovered with accuracies under $1 \mathrm{ppm}$ and $100 \mathrm{~K}$, respectively [4], [26]. It should be noticed that the chemiluminescence by species other than soot is neglected within the spectral ranges probed $(500-700 \mathrm{~nm})$. This assumption is backed by the high-energy broadband nature of soot emission, while interfering gaseous species in this region of the visible spectrum such as $\mathrm{C}_{2}$ marginally contribute to the overall radiation. This is supported by the fine agreement between the distributions of soot temperature as obtained by the BMAE and the Spectral Modulated Absorption Emission (SMAE) techniques [26]. Indeed, the narrow bands used by the SMAE, i.e. $645 \pm 5 \mathrm{~nm}$ and $785 \pm 5 \mathrm{~nm}$, were selected to get signals freed from the influence of the aforementioned interfering species.

Figure 1 shows the experimental fields of SVF at different pressure levels. As expected, SVF increases with pressure. The SVF peak is enhanced from $2.29 \mathrm{ppm}$ at $P=50.7 \mathrm{kPa}$ to 28.6 ppm at $P=121.6 \mathrm{kPa}$. The flames at $P=95 \mathrm{kPa}$ can be considered as incipient smoking, delimiting the transition between the non-smoking flames for $P<95 \mathrm{kPa}$ and the smoking ones for $P \geq 95 \mathrm{kPa}$. The radiative cooling responsible for the soot oxidation quenching at the flame tip and the resulting transition from a non-smoking flame to a smoking one is illustrated in Fig. $\mathrm{S} 1$ in the supplementary material. The temperature at the tip of the soot oxidation region is 
about $1750 \mathrm{~K}$ at pressure of $70.9 \mathrm{kPa}$ and is reduced to about $1450 \mathrm{~K}$ for the incipient smoking flame at $95 \mathrm{kPa}$.
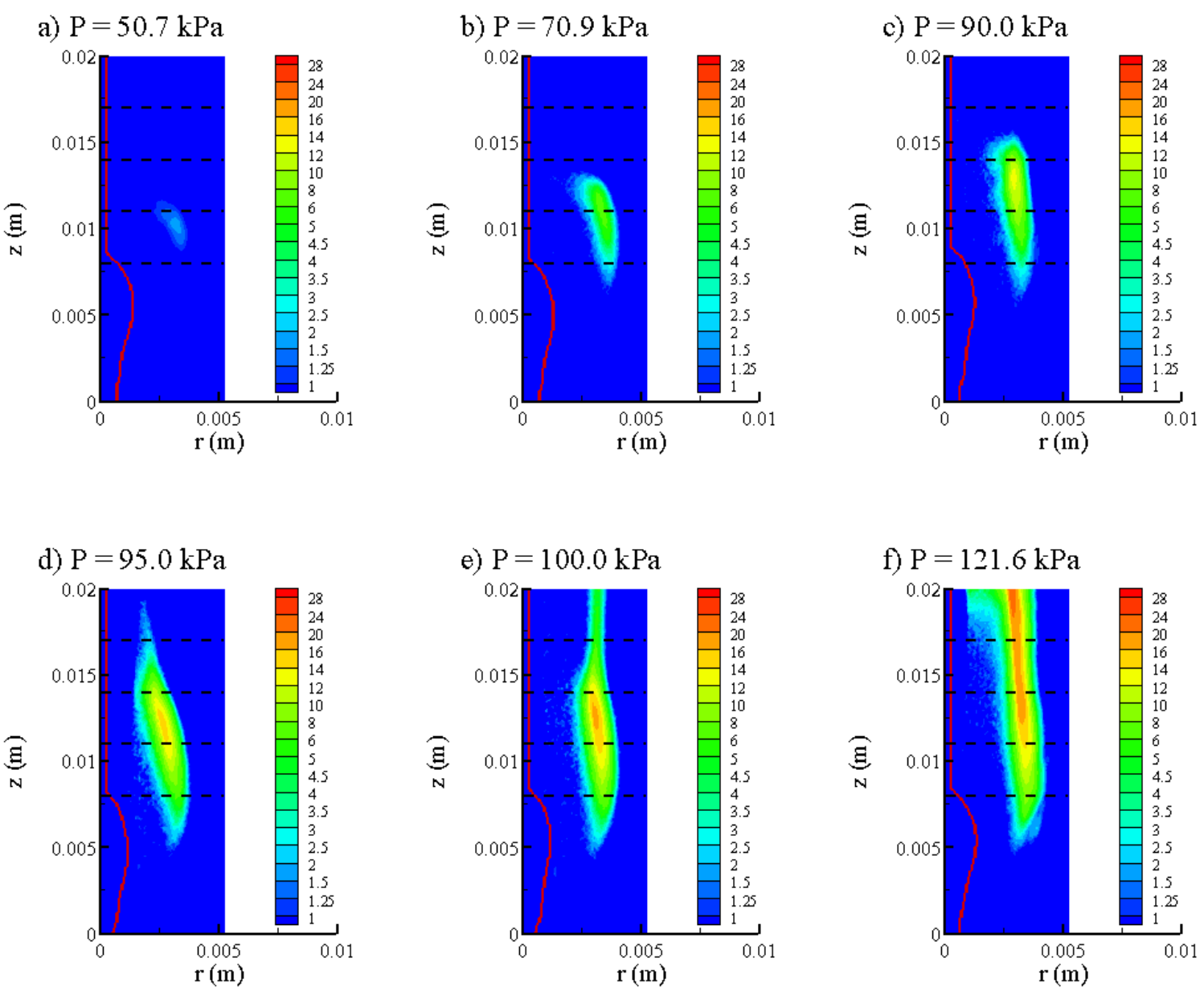

Figure 1. Fields of experimental SVF (in ppm) as a function of pressure $P$. The horizontal dashed lines represent the locations of comparison with the numerical model. The red solid line represents the wire surface, with a distinctive melted LDPE droplet contour.

\section{Numerical model}

\subsection{Governing equations}

The model solves the steady-state governing equations of both gaseous and solid phases in a flame-fixed axisymmetric coordinate system [6]. 
A detailed description of the solid phase degradation model can be found in Ref. [6] and only a summary is given here. The study focuses on gas phase processes with a special emphasis on soot production and radiative heat transfer. Consequently, the solution of the conjugated heat transfer problem at the gas/solid interface is only needed to specify proper boundary conditions for the gas phase. The problem is simplified by specifying the spread rate, the pyrolysis rate and shape of the molten LDPE droplet as inputs from the steady spreading experimental data. Based on experimental observations, the molten balls were assumed to have the same shape and size within the range of pressures investigated in the present study (see Fig. S2 in the supplementary materials). The condensed phase is then divided into three regions (see Figs. 1 and S2 for illustration). The first region is the unburnt insulated wire located ahead of the pyrolysis front $(z \leq 0)$. The second region is the molten ball where pyrolysis is assumed to occur. The fuel injection velocity profile, $u_{F}(z)$, is inferred from the measured fuel mass flow rate, $\dot{m}_{p}$, the ball surface, $S_{b}$, and the stand-off distance, $\delta(z)$. The analysis, described in Ref. [6], is based on the classical result of the reactive-laminar boundary layer theory, showing that the pyrolysis mass flow rate per unit area, $\dot{m}_{p}^{\prime \prime}$, is inversely proportional to the stand-off distance [37]. The third region is the bare nickel-chrome core $\left(z>z_{b}\right)$ where $z_{b}$ denotes the delimitation between the molten ball and the bare core. The axisymmetric heat transfer equation for both the metal core and LDPE is solved without introducing the thermally thin approximation, based on past observation of radial thermal gradient in this configuration [6]. Both melting and pyrolysis processes are assumed to be phase transition. The PE can be into three states depending on the local temperature. First, in a solid phase if the temperature is lower than the melting temperature, $T_{\text {melt }}$. Second, at the transition if the temperature is equal to $T_{\text {melt }}$. Third, in the molten phase if the temperature is higher than $T_{\text {melt }}$. The melting point of LDPE is assumed to occur at $T_{\text {melt }}=403 \mathrm{~K}$ [4], [6] and different thermal properties are used for the solid and the molten LDPE [6]. During the melting stage, the thermal properties are computed using a mass- 
weighted average between the properties of solid and those of the molten LDPE [6]. The pyrolysis is assumed to occur at the ball surface at a fixed temperature, $T_{p}=760 \mathrm{~K}$. All the thermal constants for the LDPE, including density, conductivity and heat capacity of both virgin and molten LDPE, temperature and heat of melting and pyrolysis temperature were taken from thermal analysis [4],[6],[38]. The emissivity was set equal to 1 for both solid and molten LDPE as well as for the $\mathrm{NiCr}$ along the bare wire. This simplification ignores the spectral dependency of the emissivity as well as its alteration resulting from the possible deposit of soot.

The numerical model solves the Navier-Stokes equations and transport equations for gas-phase species mass fractions and energy. More details concerning the numerical methods and the strategy for handling the stiffness of the equation system are given in Ref. [39].

A detailed modeling of diffusion flames fueled by gaseous pyrolysis products released from solids is challenging. In the case of LDPE, the composition of the gaseous pyrolysis products is complex and temperature-dependent [40]. In addition, the compositions reported in the literature may not be accurate enough, especially in terms of soot precursors, to be used as inputs data for detailed chemical mechanisms. Finally, detailed chemical mechanisms for such mixtures may be not available. The strategy adopted in the present study is inspired from that used by Zhang et al. [41] and Markan et al. [42] to develop the Burning Rate Emulator (BRE) to simulate the burning of condensed fuels. These authors identified four key parameters that have to be preserved to mimic the burning of solids: the heat of combustion (or similarly the oxygen-fuel mass ratio) to preserve the flame structure, the laminar smoke point height to preserve the fuel sooting propensity, the surface temperature to preserve surface heat loss by re-radiation and the heat of gasification to preserve the pyrolysis mass flow rate. As discussed previously, the pyrolysis mass flow rate and the surface temperature of the pyrolysing surface were imposed in the present study from experimental data. Pure ethylene is a relevant candidate 
to represent the pyrolysis products of LDPE since both species exhibit very similar heat of combustion with a discrepancy lower than $10 \%$ and the same oxygen-fuel mass ratio [43]. This assumption, adopted in previous studies, is supported by the good agreement observed in Ref. [6] between predicted and measured temperature and stand-off distance. Finally, the fuel sooting propensity of LDPE will be preserved by using its smoke point length in the sooting model (see Section 3.2). The oxidation of ethylene is modeled using the full chemical kinetic scheme developed by Qin et al. [44].

\subsection{Soot production model}

A modified two-equation soot production model, based on transport equations for soot number density per unit mass of mixture $\left(N_{S}\right)$ and soot mass fraction $\left(Y_{S}\right)$, is proposed. The source term, $\dot{\omega}_{Y_{S}}=\dot{\omega}_{s f}-\left(\dot{\omega}_{O_{2}}+\dot{\omega}_{O H}\right) A_{S}$, accounts for soot formation and oxidation by $\mathrm{O}_{2}$ and $\mathrm{OH}$, with $A_{S}$ being the soot surface area.

The LSP based soot formation (SF) model proposed by Lautenberger et al. [45] is used to compute $\dot{\omega}_{s f}=f_{s f}(\xi) g_{s f}(T)$, where $\xi$ and $T$ represent mixture fraction and temperature, respectively. $f_{s f}$ and $g_{s f}$ are cubic functions whose coefficients are determined by specifying the value and slope of the polynomials at the peak and at the lower and higher limits of the SF process. The model constants, calibrated in Ref. [45], are kept unchanged in the present study. The model is generalized to an arbitrary fuel by relating the peak of SF rates, $\dot{\omega}_{s f, P}$, to the LSP height [45]:

$$
\dot{\omega}_{s f, P}=1.1 \frac{l_{s p, C_{2} H_{4}}}{l_{s p, P E}}\left(\frac{W_{C_{2} H_{4}}}{W_{P E}}\right)\left(\frac{P}{P_{0}}\right)^{n}
$$

where $l_{s p, C_{2} H_{4}}$ and $l_{s p, P E}$ are the LSP heights of ethylene and PE equal to $0.106 \mathrm{~m}$ and $0.045 \mathrm{~m}$, respectively [43]. $P$ is the local pressure whereas $P_{0}$ is the reference one $(101.3 \mathrm{kPa})$. The 
exponent $n$ was set equal to 2 in the initial model formulation [45] based on the analysis provided in Ref. [46] from the early experimental data of Refs. [47] and [48]. However, recent experiments in laminar axisymmetric coflow diffusion flames at normal gravity showed that this exponent depends on both the fuel and pressure range [16]-[18]. In the present study, it will be calibrated from an analysis of the experimental data (see Section 4.1). $W_{C_{2} H_{4}}$ and $W_{P E}$ represent the molecular weights of ethylene and pyrolysis products of $\mathrm{PE}$, respectively. The accepted vaporization mechanism of PE considers that it vaporizes as higher molecular weight oligomers than as monomers [43]. As discussed in Section 3.1, the composition of the pyrolysis products and, in turn, $W_{P E}$ are tricky to estimate. As a consequence, the ratio $W_{C_{2} H_{4}} / W_{P E}$ was disregarded in Eq. (1) and the constant 1.1 was recalibrated to match the experimental SVF peak for the flame at $\mathrm{P}=101.3 \mathrm{kPa}$. The calibrated constant was found equal to 0.5 .

The soot oxidation rates by $\mathrm{OH}$ and $\mathrm{O}_{2}$ optimized by Guo et al. [49] were considered. This amounts to model $\dot{\omega}_{O H}$ by the Fenimore and Jones expression [50] with a revised collision efficiency of 0.10 whereas $\dot{\omega}_{O_{2}}$ is computed as $\dot{\omega}_{O_{2}}=A_{O_{2}} P_{O_{2}} T^{-0.5} \exp \left(-E_{A, O_{2}} / R_{u} T\right)$ with $P_{O_{2}}$ and $R_{u}$ being the partial pressure of $O_{2}$ and the universal gas constant, respectively.

The source term, $\dot{\omega}_{N_{S}}$, for the soot number density is given by $\dot{\omega}_{N_{S}}=N_{A} / N C_{\min } \dot{\omega}_{n}-\dot{\omega}_{\text {coag }}$ where $N_{A}$ and $N C_{\text {min }}=60$ are the Avogadro number and the number of carbon atoms in the incipient soot particle [51], respectively. The acetylene-based inception model developed by Lindstedt [51] is revised by multiplying the initial formulation by $l_{s p, C_{2} H_{4}} / l_{s p, P E}$ to account for the difference in sooting propensity between ethylene and PE:

$$
\dot{\omega}_{n}=2 k_{1}(T) l_{s p, C_{2} H_{4}} / l_{s p, P E}\left[C_{2} H_{2}\right]
$$

$\left[\mathrm{C}_{2} \mathrm{H}_{2}\right]$ is the acetylene concentration. The kinetic parameters, $k_{1}(T)$, are those provided by Lindstedt [51]. The coagulation rate, $\dot{\omega}_{\text {coag }}$, is also computed as proposed by Lindstedt [51]. 


\subsection{Radiative model}

The Full-Spectrum Correlated-K (FSCK) is used as a gas-soot radiative property model. The spectral lines for $\mathrm{CO}_{2}$ and $\mathrm{H}_{2} \mathrm{O}$ are taken from HITEMP 2010 [52] whereas the refractive indices reported in Ref. [36] are used to compute the soot absorption coefficient.

The FS RTE is expressed as [53]:

$$
\frac{d I_{g_{0}}}{d s}+k^{*}\left(g_{0}\right) I_{g_{0}}=k^{*}\left(g_{0}\right) a\left(g_{0}\right) I_{b}(T)
$$

where $g_{0}$ corresponds to the quadrature-point of a 10-point Gauss-Chebyshev quadrature scheme, the index 0 referring to the reference state. The reference state is defined by the mole fractions of $\mathrm{CO}_{2}\left(x_{\mathrm{CO} 2}\right), \mathrm{H}_{2} \mathrm{O}\left(x_{\mathrm{H} 2 \mathrm{O}}\right)$, and the $\mathrm{SVF}\left(f_{S}\right)$ averaged over the flame volume. The reference temperature is calculated as the blackbody emission averaged temperature [53]. The stretching factor, $a\left(g_{0}\right)$, is defined as $a\left(g_{0}\right)=\frac{d g\left(k_{0}, \phi_{0}, T\right)}{d g_{0}\left(k_{0}, \phi_{0}, T_{0}\right)}$ where $\phi=\left\{x_{C O 2}, x_{H 2 O}, f_{S}, T\right\}$.

An efficient FS database was developed following the methodology proposed in Ref. [54]. Values of $k^{*}$ and $a$ are stored at the 10 quadrature points for different mixtures of $\mathrm{CO}_{2}, \mathrm{H}_{2} \mathrm{O}$, and soot. At each grid point and for each quadrature point, the values of $k^{*}$ and $a$ are extracted from the database using a linear interpolation on $x_{\mathrm{CO} 2}, x_{\mathrm{H} 2 \mathrm{O}}$, and $f_{\mathrm{S}}$, and spline interpolations on $T$ and $T_{0}$.

The RTE is solved by the Finite Volume Method [55] with an angular mesh with $12 \times 16$ control angles.

\subsection{Computational details}


Simulations are considered with an overall computational domain of $4 \mathrm{~cm}(\mathrm{r}) \times 6 \mathrm{~cm}(\mathrm{z})$. The computational domain is divided into $167(\mathrm{r}) \times 378(\mathrm{z})$ cells using a non-uniform grid. The finest resolution $(76 \mu \mathrm{m} \times 76 \mu \mathrm{m})$ is located in a region covering the molten droplet and the sooting region.

\section{Results and discussions}

\subsection{Data analysis}

The experimental data are analyzed to determine $n$ in Eq. (1). The analysis assumes that the flame spreads in an opposed flow of free stream velocity, $u_{\infty}$, over a thermally-thin cylindrical material. The surface temperature of the material, $T_{P}$, remains constant during the pyrolysis process and the gas phase conductivity, $\lambda_{f l}$, dynamic viscosity, $\mu_{f l}$, and flame temperature, $T_{f l}$, are independent of pressure. A unit Schmidt number is assumed. The gaseous fuel, $F$, reacts with the oxidizer, $O_{x}$, according to the one-step reaction $F+S O_{x} \rightarrow(1+S) P$, where $S$ is the oxidizer-fuel mass ratio.

The experimental data reported in Fig. 2 a shows that $u_{p}$ and, consequently, $\dot{m}_{p}$ are independent of pressure. A scaling analysis, similar to that presented in Ref. [56], shows that the flame length, $L_{f l}$ varies as $\frac{(1+S) \dot{m}_{p}}{\mu_{f l}}$ and, then, is independent of $P$ whereas the flame radius, $\delta_{f l}$ varies as $\sqrt{\frac{(1+S) \dot{m}_{p}}{\rho_{\infty} u_{\infty}}}$ and, then, scales with $P^{-1 / 2}$

In the present study, the characteristic length scale for soot formation, $L_{S}$, is defined as the distance from the molten droplet leading edge, where pyrolysis is supposed to first occur, to the peak of integrated SVF as prescribed in [56]. Figure 2a shows that, over the range from 70.9 $\mathrm{kPa}$ to $121.6 \mathrm{kPa}, L_{S}$ is independent of pressure. The value of $L_{S}$ at $50.7 \mathrm{kPa}$ is significantly lower than those at higher pressure. However, it should be pointed out that the measured SVF at $\mathrm{P}=50.7 \mathrm{kPa}$ becomes close to the limit of detection of the BMAE technique. These 
experimental data support that the SF residence time, defined as $t_{r e s}=L_{S} / u_{\infty}$, is also independent of pressure. Consequently, the soot particles experience the same residence time in the SF region for all the flames investigated in this study.

The conservation of SVF in a Lagrangian sense in the SF region is expressed as $\frac{D\left(\rho_{S} f_{S}\right)}{D t}=$ $\frac{D\left(\rho Y_{S}\right)}{D t}=\dot{\omega}_{s f}$. This expression can be rewritten as $\frac{D\left(\rho_{s} f_{s}\right)}{D t}=\frac{\rho_{s} f_{s, \max }}{t_{r e s}}=\dot{\omega}_{s f, P}$. As a consequence, the SVF peak, $f_{s, \max }$, scales as $P^{n}$ since $\dot{\omega}_{s f, P}$ scales as $P^{n}$ and both the soot density, $\rho_{s}$, and $t_{r e s}$ are independent of pressure. Figure $2 \mathrm{~b}$ shows the measured $f_{s, \max }$ as a function of $P / P_{0} . n$ is found to be 2.92, showing that the SF rate in the present flames is approximately third-order in pressure. This value of $n$ is used in the numerical simulations (see Eq.(1)).
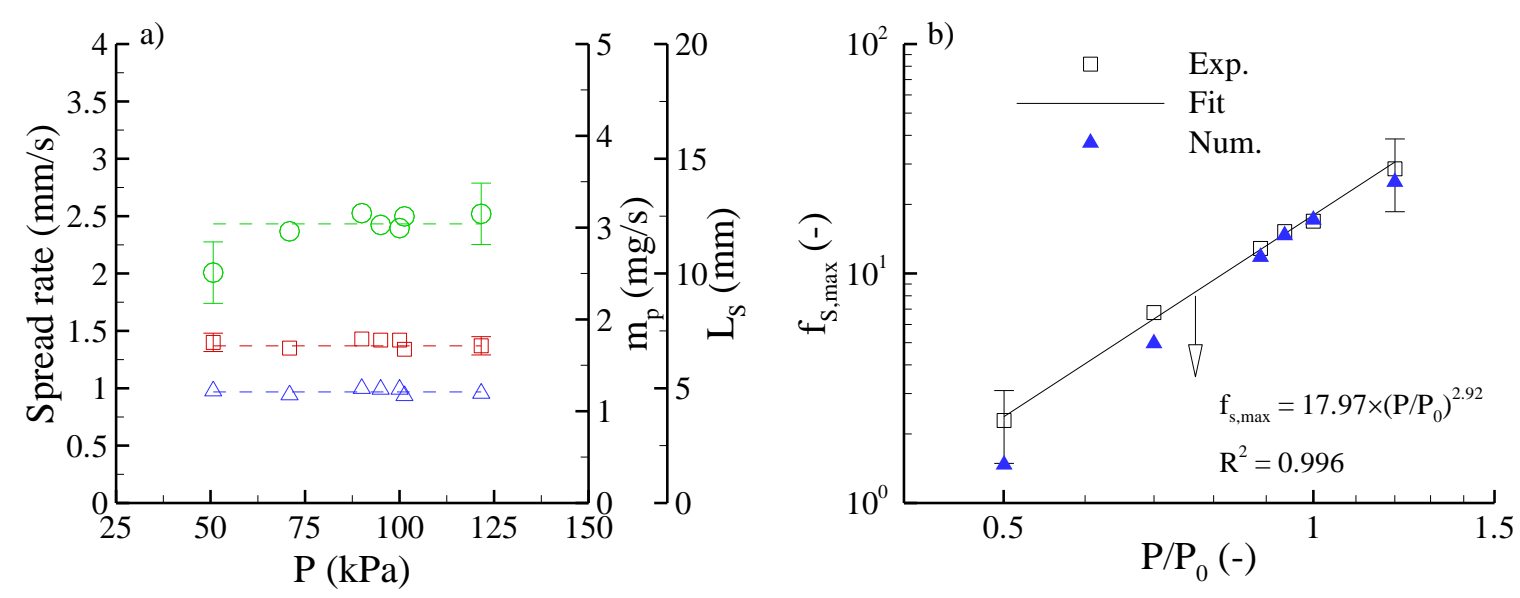

Figure 2. a) Spread rate (red square), pyrolysis mass flow rate (blue delta) and $L_{S}$ (green circle) as a function of pressure. b) Peak soot volume fraction as a function of $P / P_{0}$.

\subsection{Model validation}

Figure $2 \mathrm{~b}$ shows that predicted SVF peaks are in proper agreement with the measurements. The largest discrepancies are observed for $\mathrm{P}=50.7 \mathrm{kPa}$ with the experimental peak being underpredicted by about $36 \%$. More detailed comparisons are presented in Fig. 3 that displays radial profiles of SVF at different locations along the wire axis. Figure 1 shows that the selected 
locations at $z=8 \mathrm{~mm}, 11 \mathrm{~mm}, 14 \mathrm{~mm}$, and $17 \mathrm{~mm}$ are in the soot growth region, in the region where the SVF peaks, in the soot oxidation region, and in the region where soot is fully oxidized for the non-smoking flames, respectively. Section 4.1 revealed that, whatever the pressure, soot particles experience the same residence times at a given location along the wire axis. As a consequence, the observed increase in SVF with pressure at a given $z$ is only attributed to pressure effects. Model predictions exhibit an overall reasonable agreement with the experimental trends in each region of the flame. For a given pressure, predicted SVF increases up to $11 \mathrm{~mm}$ and then decreases as the distance is further increased in agreement with experimental data. Figure $3 \mathrm{~d}$ shows that soot is observed at $\mathrm{z}=17 \mathrm{~mm}$ only for pressure higher than $95 \mathrm{kPa}$. Therefore, the model predicts correctly that flames at $P<95 \mathrm{kPa}$ are non-smoking whereas those at $P \geq 95 \mathrm{kPa}$ are smoking (see Fig. 3d). For a given location, the increase in soot volume fraction with pressure is also well captured and the shape of the profiles as well as the peak values are in reasonable agreement with the experimental data. However, the computed maximum occurs at higher $r$ and the soot region is shifted downstream as compared to the experiments. These discrepancies become more and more pronounced as the distance along the wire axis increases.

\subsection{Effects of pressure on radiant fraction}

Model results show that, for heat transfer purposes, the flames investigated in the present study are optically-thin. Nevertheless, it should be pointed out that the optically-thin assumption may not be generalized at lower velocity since, as shown by Bedir and T'ien [57], flames thickens at low stretch rates and self-absorption may become non-negligible. The radiant fraction can then be expressed as $\chi_{R}=\frac{4 \kappa_{p} \sigma T_{f l}^{4} V_{f l}}{\dot{m}_{p} \Delta h_{c}}$. The flame volume, $V_{f l}$, is proportional to $L_{f l} \delta_{f l}^{2}$ and, according to Section 4.1, scales with $P^{-1}$. It is expected that $\chi_{R}$ depends on pressure through $\kappa_{p} V_{f l}$ and then, introducing the pressure dependence of $V_{f l}$, through $\kappa_{p} P^{-1}$ : 


$$
\chi_{R}=C \kappa_{p} P^{-1}
$$

where $C$ does not depend on pressure. Figure 4 a displays the evolution of $\chi_{R}$ as a function of $P$. The radiative loss results from the contributions of both radiating gas, $\chi_{R, g}$ and soot, $\chi_{R, s}$. The radiative loss is dominated by gas radiation $\left(\chi_{R, g}>\chi_{R, S}\right)$ for pressure lower than about 75 $\mathrm{kPa}$ whereas the soot contribution prevails for higher pressure $\left(\chi_{R, S}>\chi_{R, g}\right) . \kappa_{p}$ is proportional to $P$ for radiating gas which explains from Eq. (4) that $\chi_{R, g}$ remains constant over the range of pressure investigated (see Fig. 4a). $\kappa_{p}$ varies with pressure as $f_{s, \max }$ for soot and, then, scales with $P^{2.92}$ according to Section 4.1. This explains from Eq. (4) that $\chi_{R, S}$ scales approximately with $P^{1.92}$ (see Fig. 4a). Therefore, the observed increase in $\chi_{R}$ with $P$, from 0.17 at $P=$ $50.7 \mathrm{kPa}$ to 0.35 at $P=121.6 \mathrm{kPa}$, results specifically from an increase in the soot contribution (see Fig. 4a).

Figure 4a shows that $\chi_{R}$ at the SP transition $(P \approx 95 \mathrm{kPa})$ is close to 0.3 that is consistent with the values reported for axisymmetric laminar diffusion flames at earth gravity [21], but lower than those reported in microgravity [19]. The SP mechanism is intimately related to the increase in radiative cooling with $P$. At the SP transition, the temperature at the flame tip becomes too low to enable complete soot oxidation and soot is then released from the flame. In previous studies at earth gravity, the soot oxidation freezing temperature, $T_{s}$, was defined at the height of smoking flames where the integrated SVF starts to reach a plateau [58]. This definition is adopted in the present study and both numerical and experimental data are reported in Fig. 4b. 

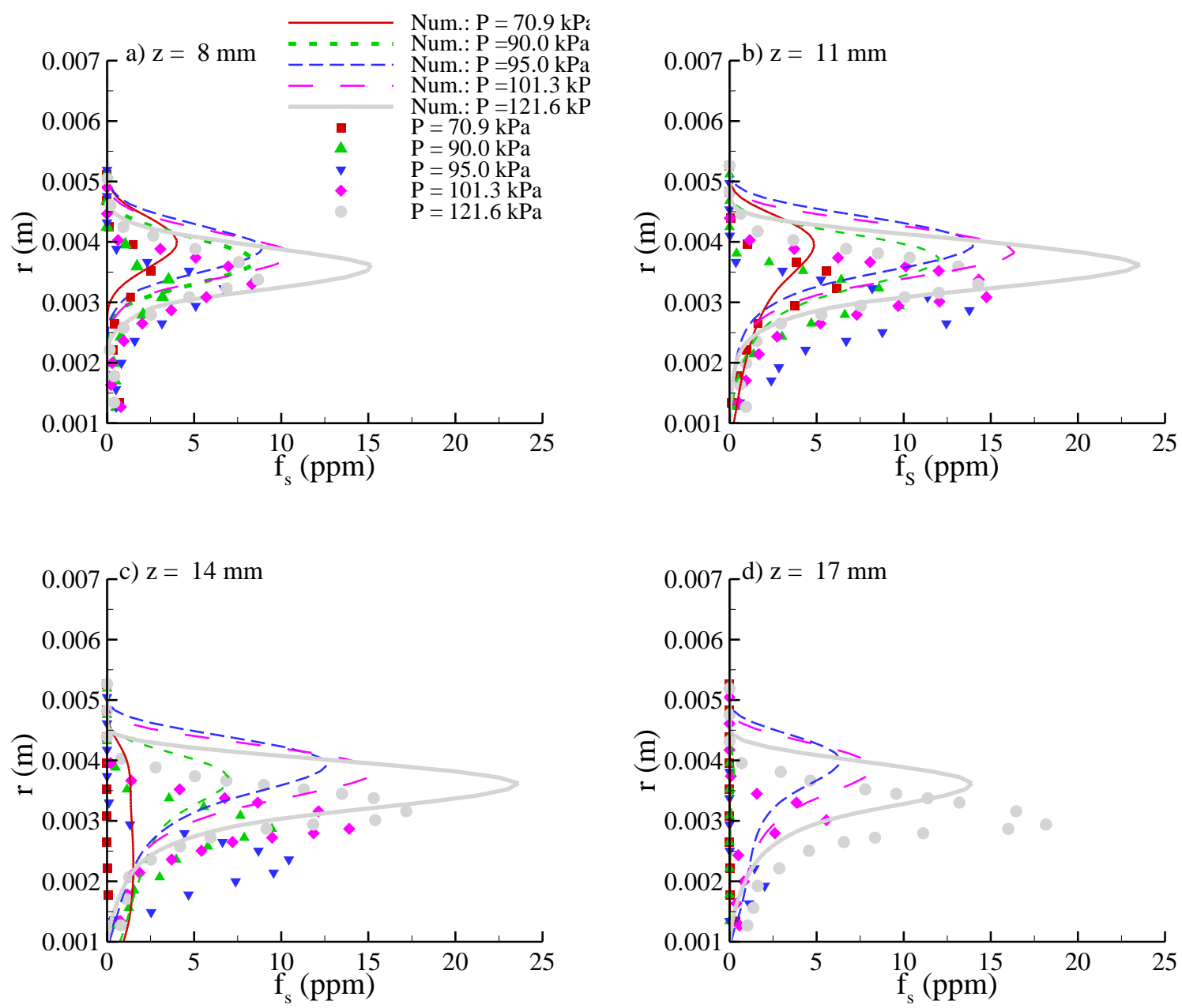

Figure 3. Radial profile of SVF at different locations along the wire axis, i.e. a) $8 \mathrm{~mm}$, b)

$11 \mathrm{~mm}, \mathrm{c}) 14 \mathrm{~mm}$, and d) $17 \mathrm{~mm}$.

Both computed and experimental soot burnout temperature stand in the range 1300-1450 K which is also consistent with recent [24] and older measurements [22],[23],[58] at earth gravity.

\subsection{Effects of pressure on the radiative feedback to the solid surface}

Figure 5 shows the incident radiative flux on the wire surface, $\dot{q}_{R, i n c}^{\prime \prime}$, as a function of the distance along the wire for different pressures. The radiative flux re-emitted by the wire surface, $\dot{q}_{R, w}^{\prime \prime}$ at $P=101.3 \mathrm{kPa}$ is also plotted in Fig. 5. The choice of this pressure does not alter the generality of the discussion since $\dot{q}_{R, w}^{\prime \prime}$ at other pressure levels behaves similarly. 

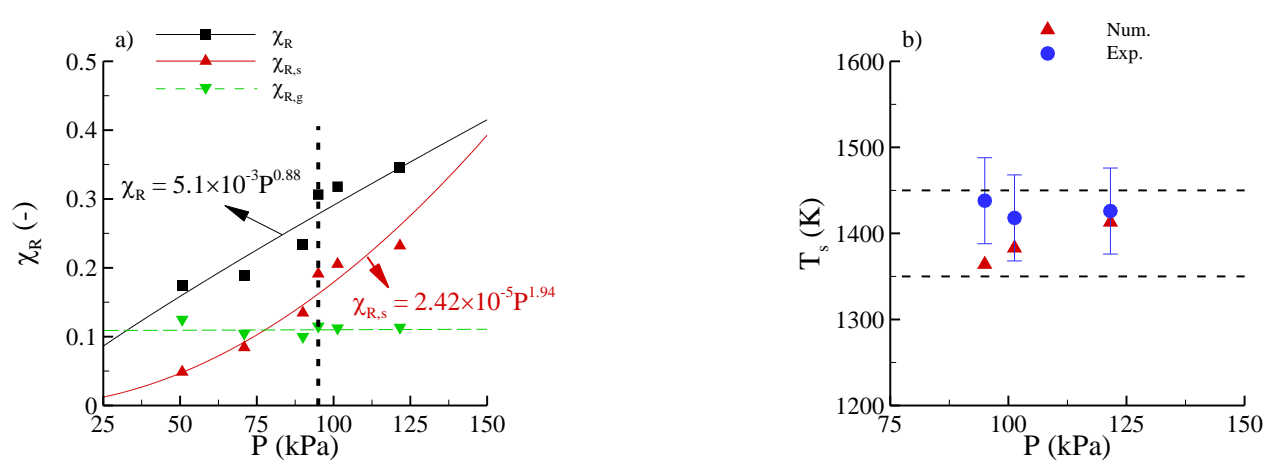

Figure 4. a) Radiant fraction and b) soot quenching temperature as a function of $P$. In Fig.4a, the dashed vertical line indicates the transition between non-smoking and smoking flames. In Fig.4b, the dashed horizontal lines delineate the range of $T_{s}$ reported at earth gravity.

Figure 5 shows that $\dot{q}_{R, i n c}^{\prime \prime}$ increases significantly with pressure owing to the enhancement in soot radiation. In the unburnt LDPE region $(z<0), \dot{q}_{R, i n c}^{\prime \prime}$ and $\dot{q}_{R, w}^{\prime \prime}$ decrease rapidly with z regardless of $P$, with $\dot{q}_{R, w}^{\prime \prime}$ being higher than $\dot{q}_{R, i n c}^{\prime \prime}$ especially at the vicinity of the molten ball leading edge. Along the molten ball $(0<\mathrm{z}<8 \mathrm{~mm}), \dot{q}_{R, i n c}^{\prime \prime}$ increases with $\mathrm{z}$ with an enhanced rate upstream $z_{b, \max }$ (see Fig. 5). On the other hand, $\dot{q}_{R, w}^{\prime \prime}$ remains constant due to the assumption of constant pyrolysis temperature. Along the bare wire $(\mathrm{z}>8 \mathrm{~mm})$, whatever $P, \dot{q}_{R, \text { inc }}^{\prime \prime}$ reaches a maximum at about $12 \mathrm{~mm}$ and decreases rapidly as $\mathrm{z}$ increases further. The location of this maximum corresponds to the SVF peak, approximately (see Fig. 1). $\dot{q}_{R, w}^{\prime \prime}$ increases also to reach a maximum at about $\mathrm{z}=19 \mathrm{~mm}$ regardless of the pressure level. This maximum corresponds to the region where the flame falls back to the wire, explaining the high temperatures of the $\mathrm{NiCr}$. Figure 5 shows that $\dot{q}_{R, w}^{\prime \prime}$ is higher than $\dot{q}_{R, i n c}^{\prime \prime}$ regardless of $P$ and the location along the wire axis. Therefore, the radiative heat transfer contributes negatively to the heating of the unburnt LDPE and to the heat balance along the pyrolyzing surface. It should be pointed out that this latter conclusion may not be generalized to other geometries or ambient conditions. 


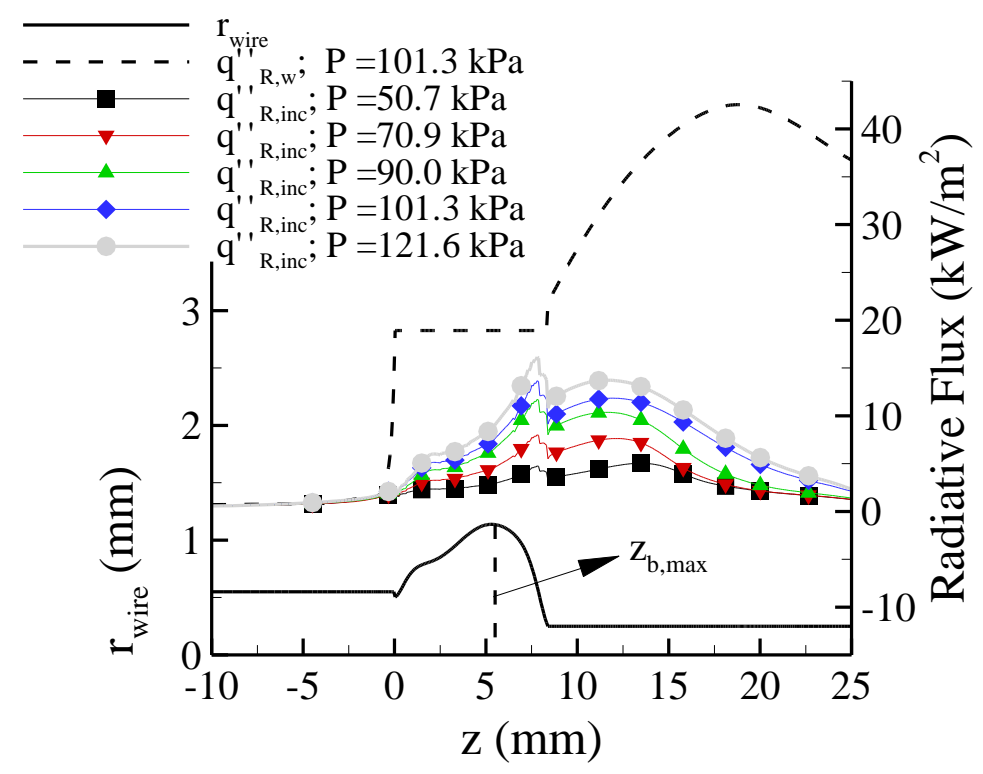

Figure 5. Incident radiative flux, $\dot{q}_{R, \text { inc }}^{\prime \prime}$, at different pressure levels and surface emission flux, $\dot{q}_{R, w}^{\prime \prime}$, at $\mathrm{P}=101.3 \mathrm{kPa}$ along the wire axis (right y-axis). The axial evolution of the wire radius,

$$
r_{\text {wire }}, \text { is also plotted (left } \mathrm{y} \text {-axis). }
$$

\section{Conclusions}

The effects of pressure on soot production and radiative heat transfer in the non-buoyant opposed-flow flame spread along NiCr wires coated with LDPE are investigated experimentally and numerically. The following conclusions can be drawn:

1) Experimental data show that spread rate, pyrolysis rate, and residence time for soot formation are independent of pressure whereas the soot formation rate is third-order in pressure.

2) A two-equation SP-based soot model is proposed and implemented in a CFD model including detailed chemistry and state-of-the-art radiation model. Model predictions are in satisfactory agreement with the available experimental data and capture the effects of pressure on soot production as well as the transition from a non-smoking to a smoking flame. 
3) The radiant fraction increases with pressure specifically as a result of an increase in soot radiation. In addition, gas radiation dominates soot radiation at pressure lower than $75 \mathrm{kPa}$ whereas the opposite trend is observed for higher pressure.

4) The radiant fraction at the SP transition, which occurs at $95 \mathrm{kPa}$, approximately, is about 0.3 and the soot oxidation freezing temperature is found to be in the range 1350-1450 K. These data are consistent with those previously reported at earth gravity.

5) Whatever the pressure considered, the surface re-radiation dominates the incident radiative flux from the flame along the entire wire.

\section{Acknowledgments}

The authors feel grateful to the Centre National d'Etudes Spatiales for its financial support under Contract No. 130615.

\section{References}

[1]. P.S. Greenberg, K.R. Sacksteder, T. Kashiwagi, The USML-1 Wire insulation Flammability Glovebox Experiment, Third International Microgravity Combustion Workshop 2, NASA Lewis Research Center, Cleveland, 1994, p. 25-30.

[2]. M. Kikuchi, O. Fujita, K. Ito, A. Sato, T. Sakuraya, Experimental study on flame spread over wire insulation in microgravity, Proc. Combust. Inst. 27 (1998) 2507-2514.

[3]. O. Fujita, K. Nishizawa, K. Ito, Effect of low external flow on flame spread over polyethylene-insulated wire in microgravity, Proc. Combust. Inst. 29 (2002) 2545-2552.

[4]. A. Guibaud, J.M. Citerne, J.L. Consalvi, O. Fujita, J.L. Torero, G. Legros, Experimental evaluation of flame radiative feedback: methodology and application to opposed flame spread over coated wires in microgravity, Fire Technol. 56 (2019) 185-207. 
[5]. S. Takahashi, H. Takeuchi, H. Ito, Y. Nakamura, O. Fujita, Study on unsteady molten insulation volume change during flame spreading over wire insulation in microgravity, Proc. Combust. Inst. 34 (2013) 2657-2664.

[6]. A. Guibaud, J.L. Consalvi, J.M. Orlac'h, J.M. Citerne, G. Legros, Soot production and radiative heat transfer in opposed flame spread over a polyethylene insulated wire in microgravity, Fire Technol. 56 (2019) 287-314.

[7]. D.L. Urban, P. Ferkul, S. Olson, G.A. Ruff, J. Easton, J.S. T’ien, Y.T.T. Liao, C. Li, C. Fernandez-Pello, J.L. Torero, G. Legros, C. Eigenbrod, N. Smirnov, O. Fujita, S. Rouvreau, B. Toth, G. Jomaas, Flame spread: Effects of microgravity and scale, Combust. Flame 199 (2019) $168-182$.

[8]. B.L. Diamant, W.R. Humphries, Past and present environmental control and life support systems on manned spacecraft. SAE Transactions 99 (1990), 376-408.

[9]. J. Lovell, J. Kluger, Apollo 13, Houghton Mifflin Harcourt (2006).

[10]. G.S. Ivanovich, Salyut - The First Space Station: Triumph and Tragedy, Springer Science \& Business Media (2008).

[11]. A. A. Siddiqi, Challenge to Apollo: the Soviet Union and the space race, 1945-1974, NASA History Series (2000).

[12]. J.E. Oberg, Star-crossed orbits: inside the US-Russian space alliance, McGraw-Hill Companies (2002).

[13]. R. Friedman, Risks and issues in fire safety on the space station, NASA Technical Reports (1994).

[14]. P. Baker, The Story of Manned Space Stations: An Introduction, Springer Science \& Business Media (2007).

[15]. S. Garber, Jerry Linenger: Fire and Controversy January 12 - May 24, NASA History Program Office (1997). 
[16]. A.E Karatas, Ö.L. Gülder, Soot formation in high pressure laminar diffusion flames, Prog. Energy Combust. Sci. 38 (2012) 818-845.

[17]. L.L. McCrain, W.L. Roberts, Measurements of the soot volume field in laminar diffusion flames at elevated pressures, Combust. Flame 140 (2005) 60-69.

[18]. A.E. Daca, Ö.L. Gülder, Soot formation characteristics of diffusion flames of methane doped with toluene and n-heptane at elevated pressures, Proc. Combust. Inst 36 (2017) 737744.

[19]. D.L. Urban, Z.G. Yuan, P.B. Sunderland, G.T. Linteris, J.E. Voss, K.C. Lin, Z. Dai, K. Sun, G.M. Faeth, Structure and soot properties of nonbuoyant ethylene/air laminar jet diffusion flames, AIAAJ 36 (8) (1998) 1346-1360.

[20]. D.L. Urban, Z.-G. Yuan, P.B. Sunderland, K.-C. Lin, Z. Dai, G.M. Faeth, Smoke- point properties of nonbuoyant round laminar jet diffusion flames, Proc. Combust. Inst. 28 (2000) $1965-1972$.

[21]. G.H. Markstein, Relationship between smoke point and radiant emission from buoyant turbulent and laminar diffusion flames, Proc. Combust. Inst. 20 (1984) 1055-1061.

[22]. G.H. Markstein, J. de Ris, Radiant emission and absorption by ethylene and propylene diffusion flames, Proc. Combust. Inst. 20 (1984) 1637-1646.

[23]. J.H. Kent, H.G. Wagner, Why do diffusion flames emit smoke? Combust. Sci. Technol. 41 (1984) 245-269.

[24]. J. Bonnety, A. Guibaud, R. Jalain, A. Matynia, J.L. Consalvi, F. Liu, G. Legros, Probing the local radiative quenching during the transition from a non-smoking to a smoking laminar coflow ethylene/air non-premixed flame, Combust. Flame 203 (2019) 120-129.

[25]. S.L. Olson, F.J. Miller, S. Jahangirian, I. S. Wichman, Flame spread over thin fuels in actual and simulated microgravity conditions, Combust. Flame 156 (2009), 1214-1226. 
[26]. A. Guibaud, J.M. Citerne, J.M. Orlac'h, O. Fujita, J.L. Consalvi, J.L. Torero, G. Legros, Broadband modulated absorption/emission technique to probe sooting flames: Implementation, validation, and limitations, Proc. Combust. Inst. 37 (2019) 3959-3966.

[27]. M.W. Stavnes, A.N. Hammoud, R.W. Bercaw, Operational Environments for Electrical Power Wiring on NASA Space Systems, NASA Technical Memorandum 106655, 1994.

[28]. N.N. Bakhman, L.I. Aldabaev, B.N. Kondrikov, V. A. Filippov, Burning of polymeric coatings on copper wires and glass threads: I. Flame propagation velocity. Combust. Flame 41 (1981) 17-34.

[29]. R. Friedman, Fire safety in spacecraft, Fire and Meterials 20 (1996) 35-243.

[30]. P. Ferkul, K.R. Sacksteder, P.S. Greenberg, D.L. Dietrich, H.D. Ross, J.S. T'ien, R. A. Altenkirch, L. Tang, M. Bundy, M. Delichatsios, Combustion experiments on the Mir space station, AIAA-99-0439.

[31]. X. Huang, Y. Nakamura, F. A. Williams, Ignition-to-spread transition of externally heated electrical wire, Proc. Combust. Inst. 34 (2013) 2505-2512.

[32]. J.M. Citerne, H. Dutilleul, K. Kizawa, M. Nagachi, O. Fujita, M. Kikuchi, G. Jomaas, S. Rouvreau, J.L. Torero, G. Legros, Fire safety in space - investigating flame spread interaction over wires, Acta Astronaut. 126 (2016) 500-509.

[33]. L. Hu, L. Yong, K. Yoshioka, Z. Yangshu, C. Fernandez-Pello, C.S. Ho, O. Fujita, Limiting oxygen concentration for extinction of upward spreading flames over inclined thin polyethylene-insulated $\mathrm{NiCr}$ electrical wires with opposed-flow under normal- and microgravity, Proc. Combust. Inst. 36 (2017) 3045-3053.

[34]. M. Nagachi, F. Mitsui, J.M. Citerne, H. Dutilleul, A. Guibaud,G. Jomaas, G. Legros, N. Hashimoto, O. Fujita, Can a spreading flame over electric wire insulation in concurrent flow achieve steady propagation in microgravity?, Proc. Combust. Inst. 37 (2019) 4155-4162. 
[35]. C. Harrison, S. Weaver, C. Bertelsen, E. Burgett, N. Hertel, E. Grulke, Polyethylene/boron nitride composites for space radiation shielding, J. App. Polymer Sci. 109 (2008) 2529-2538.

[36]. H. Chang, T. Charalampopoulos, Determination of the wavelength dependence of refractive indices of flame soot, Proc. R. Soc. 430 (1990) 577-591.

[37]. H.W. Emmons, The Film Combustion of Liquid Fuel. Zeitschrift für angewandte Mathematik und Mechanik 36 (1956) 60-71.

[38]. The National Institute of Advanced Industrial Science and Technology, available at http://riodb.ibase. aist.go.jp/ptdb/entarupi.htm.

[39]. H. Guo, F. Liu F, G.J. Smallwood, Ö.L. Gülder, Numerical study on the influence of hydrogen addition on soot formation in a laminar ethylene-air diffusion flame, Combust. Flame 145 (2006) 324-338.

[40]. S. Lovett, F. Berruti, L.A. Behie, Ultrapyrolytic upgrading of plastic wastes and plastics/heavy oil mixtures to valuable light gas products, Ind. Eng. Chem. Res. 36 (1997), 4436-4444.

[41]. Y. Zhang, M. Kim, P.B. Sunderland J.G. Quintiere, J. de Ris, A burner to emulate condensed phase fuels. Exper. Thermal Fluid Sci. 73 (2016) 87-93.

[42]. A. Markan, P.B. Sunderland, J.G. Quintiere, J.L. de Ris, D.P. Stocker, H.R. Baum, A Burning Rate Emulator (BRE) for study of condensed fuel burning in microgravity, Combust. Flame 192 (2018) 272-282.

[43]. M.M. Khan, A. Tewarson, M. Chaos M, Combustion Characteristics of Materials and Generation of Fire Products, In MJ Hurley (ed) SFPE Handbook of Fire Protection Engineering, $5^{\text {th }}$ Edition, Springer, New York, pp. 1143-1232, 2016. 
[44]. Z. Qin, V.V. Lissianski, H. Yang, W.C. Gardiner, S.G. Scott, H. Wang, Combustion chemistry of propane: a case study of detailed reaction mechanism optimization, Proc. Combust. Inst. 28 (2000) 1663-1669.

[45]. C.W. Lautenberger, J.L. de Ris, N. Dembsey, J.R. Barnett, H.R. Baum, A simplified model for soot formation and oxidation in CFD simulation of non-premixed hydrocarbon flames, Fire Safety J. 40 (2005) 141-176.

[46]. J.L. de Ris, P.K. Wu, G. Heskestad, Radiation Fire Modelling, Proc. Combust. Inst. 28 (2000) 2751-2759.

[47]. R.L. Schalla, T.P. Clark, G.E. McDonald, Formation and combustion of smoke in laminar flames, NACA Technical Report 1186, 1954.

[48]. W.L. Flower, C.T. Bowman, Soot production in axisymmetric laminar diffusion flames at pressures from one to ten atmospheres, Proc. Combust. Inst. 21 (1988) 1115-1124.

[49]. H. Guo, P.M. Anderson, P.B. Sunderland, Optimized rate expressions for soot oxidation by $\mathrm{OH}$ and $\mathrm{O}_{2}$, Fuel 172 (2016) 248-252.

[50]. C.P. Fenimore, G.W. Jones, Oxidation of soot by hydroxyl radicals, J. Phys. Chem. 71 (1967) 593-597.

[51]. R.P. Lindstedt, Simplified soot nucleation and surface growth steps for non-premixed flames, in Soot Formation in Combustion, H. Bockhorn, ed., Springer-Verlag, Berlin, 1994, 417-441.

[52]. L.S. Rothman, I.E. Gordon, R.J. Barber, H. Dothe, R.R. Gamache, A. Goldman, VI. Perevalov, S.A. Tashkun, J. Tennyson, HITEMP: The High-Temperature Molecular Spectroscopic Database. J. Quant. Spectrosc. Radiat. Transf. 111 (2011) 2139-2150.

[53]. M.F. Modest, R.J. Riazzi, Assembly Full Spectrum k-Distribution from a Narrow Band Database: Effects of Mixing Gases, Gases and Non-Gray Absorbing Particles and Non-Gray Scatters in Non-Gray Enclosures, J. Quant. Spectrosc. Radiat. Transf. 90 (2005) 169-189. 
[54]. C. Wang, M.F. Modest, B. He, Full-spectrum k-distribution look-up table for non homogeneous gas-soot mixtures, J. Quant. Spectrosc. Radiat. Transf. 176 (2016) 129-136.

[55]. E.H. Chui, G.D. Raithby, P.M.J. Hughes, Prediction of Radiative Transfer in Cylindrical Enclosures with the Finite Volume Method, AIAA J. Thermophys. Heat Transf. 6 (1992) 605611.

[56]. J. Contreras, J.L. Consalvi, A. Fuentes, Oxygen index effect on the structure of a laminar boundary layer diffusion flame in a reduced gravity environment, Proc. Combust. Inst. 36 (2017) 3237-3247.

[57]. H. Bedir, J.S. T'ien, A computational study of flame radiation in PMMA diffusion flames including fuel vapour participation, Proc. Combust. Inst. 27 (1998) 2821-2828.

[58]. J.H. Kent, H.G. Wagner, Temperature and fuel effects in sooting diffusion flames, Proc. -Combust. Inst. 20 (1985) 1007-1015. 